\title{
O TUMULUS 1 DO SOUTO (ABRANTES, MÉDIO TEJO): NOVOS CON- TRIBUTOS PARA O CONHECIMENTO DAS MATERIALIDADES DO MUNDO FUNERÁRIO DO BRONZE FINAL NO CENTRO DE PORTUGAL
}

\author{
MASSIMO BELTRAME ${ }^{(1),(2)}$, CARLO BOTTAINI ${ }^{(1),(2)}$, ANA CRUZ ${ }^{(3),(4)(5),(6)}$, RAQUEL VILAÇA $^{(7),(8)}$, ANTÓ- \\ NIO CANDEIAS ${ }^{(1)} \&$ JOSÉ MIRÃO $^{(1)}$
}

Resumo:

\begin{abstract}
$\mathrm{O}$ artigo apresenta e discute os resultados obtidos das análises arqueométricas realizadas sobre 4 fragmentos de metal, fragmento de cerâmica de uma grande urna e sobre as marcas/incrustações encontradas na superfície de um pequeno púcaro procedentes de um contexto funerário de incineração atribuído ao Bronze Final (BF), o Tumulus 1 do Souto (Abrantes, Centro de Portugal). O sítio arqueológico e os materiais recuperados já foram publicados por um dos autores, mas o estudo arqueométrico dos materiais, em particular dos fragmentos de metais e das cerâmicas nunca foi efetuado. De acordo com uma abordagem multi-analítica recorreu-se a diversas técnicas analíticas, nomeadamente Espectrometria de Raios-X Portátil (pXRF), Microscopia Eletrónica de Varrimento acoplada a Detector de Raios-X por Dispersão de Energias (SEM-EDS), Microscopia óptica (MO) e Difração de Raios-X (XRD). Os resultados obtidos determinaram a proveniência da grande urna, provavelmente produzida com materiais encontrados num raio de 10-15 km do sítio arqueológico. A composição química e as características dos fragmentos de metal analisados indicam tratar-se de uma liga binária $(\mathrm{Cu}+\mathrm{Sn})$ com pequenas inclusões de elementos secundários como prata, arsénio e ferro. O estudo também evidenciou, na superfície do pequeno púcaro, a presença de uma patina metálica. A combinação dos dados arqueológicos e arqueométricos permitiu aumentar o conhecimento do estado da arte no contexto funerário de cremação com deposição em urna, típico da Idade do Bronze no Oeste da Península Ibérica, especialmente no médio Tejo.
\end{abstract}

Palavras-chave: Incineração, Tumulus, Bronze Final, Arqueometria, Portugal Central.

Abstract:

\begin{abstract}
The Tumulus 1 of Souto (Abrantes, Midlle Tagus): New contributions to the knowledge of the materiality of the Late Bronze Age funerary world in Central Portugal

This paper presents and discusses the results obtained from the archaeometrical analysis of 4 fragments of metal, fragment of a big cinerary urn as well as the metallic incrustations observed on the surface of a small jug. The materials were recovered in the Tumulus 1 of Souto (Abrantes, Central Portugal), a funerary structure dated to the end of the Bronze Age. The archaeological site and the material recovered have already been published by one of the authors; however, the archaeometrical study of the materials, in this case metal fragments and ceramic shards, were never performed. The study adopted a multi-analytical experimental protocol which provide for the use of portable XRF spectroscopy (pXRF), scanning electron microscopy couple whit an energy dispersive X-Ray detector (SEMEDS), optical microscopy (OM), X-Ray diffraction (XRD). The results obtained have determined the provenance of the big urn, probably produced with materials recovered in a radius of $10-15 \mathrm{~km}$ from the archaeological site. The chemical composition of the metal fragments point to a binary alloy $(\mathrm{Cu}+\mathrm{Sn})$ with sporadic inclusions of silver, arsenic and iron. The study also evidenced, on the surface of the small jug, the presence of a metallic patina. The combination of archaeological and archaeometrical data implement the state of the art for the understanding of Western Iberia cremation funerary context during the Bronze Age, especially in the middle Tagus valley.

Keywords: Incineration, Tumulus, Late Bronze Age, Archaeometry, centre of Portugal
\end{abstract}

\section{INTRODUÇÃO}

O presente texto tem como objetivo principal a divulgação dos resultados arqueométricos relativos aos materiais recolhidos no decorrer da escavação do Tumulus 1 do Souto, nomeadamente alguns fragmentos de metal, um púcaro e um fragmento de cerâmica pertencente à grande urna onde os materiais foram guardados, conforme revelou o trabalho de campo.

Este é um monumento funerário inédito do ponto de vista do seu conteúdo, para a Idade do
Bronze Final; não tanto pela grande urna, que parece já ter sido utilizada no quotidiano, mas antes, pela colocação (no interior) de um pequeno púcaro com incrustações metálicas na superfície exterior. Dentro da grande urna, e parcialmente no interior do púcaro, foram colocados elementos metálicos, alguns frutos carbonizados criteriosamente recolhidos (QUeIrOZ, P. \& CRUZ, A. 2018) e restos osteológicos (TOMÉ 2008). O monumento tumulus 1 do Souto foi intervencionado no âmbito do projecto "Sistemas de Povoamento e Subsistência - sequências culturais na transição entre o Mesolítico e o

\footnotetext{
(1) Laboratório HERCULES, Universidade de Évora

${ }^{(2)}$ CIDEHUS, Universidade de Évora

${ }^{(3)}$ Centro Transdisciplinar das Arqueologias do Instituto Politécnico de Tomar

(4) Unidade de Arqueologia da ESCVA da Universidade de Trás-os-Montes e Alto Douro

${ }^{(5)}$ Centro de Tecnologia, Restauro e Valorização das Artes - Techn\&Art

(6) ARKWORK - WG1- COST Action - CA 15201 - Archaeological practices and knowledge work in the digital environment

(7) Instituto de Arqueologia da Faculdade de Letras da Universidade de Coimbra
}

${ }^{(8)}$ Centro de Estudos em Arqueologia, Artes e Ciências do Património 
Calcolítico no Ribatejo (SIPOSU MC). Os trabalhos decorreram em Outubro de 2008 , tendo sido realizados por uma equipa do ex-Centro de PréHistória do Instituto Politécnico de Tomar, constituída por alunos de Arqueologia com a coordenação de Ana Cruz. Os dados de natureza arqueológica foram previamente discutidos e publicados (CRUZ 2011; CRUZ \& GRAÇA 2013; CRUZ et al. 2013; CRUZ et al. 2014A; CRUZ et al. 2014B; CRUZ et al. 2015; CRUZ 2016A; CRUZ 2016B; DELFINO et al.2014; QUEIROZ \& CRUZ 2018).

\section{LOCALIZAÇÃO E CONTEXTO ARQUEOLÓGICO}

O tumulus 1 de Souto é um pequeno monumento de planta subcircular, distando cerca de 5,5 $\mathrm{m}$ do tumulus 2 e cerca de $500 \mathrm{~m}$ dos tumuli $3,4 \mathrm{e}$ 5 , que se encontram adossados uns aos outros. Um pouco mais distante, e isolado, encontra-se o tumulus 6. Estes seis monumentos formam no seu conjunto a área da necrópole do Souto.

O tumulus 1 do Souto situa-se na zona norte do concelho de Abrantes na bacia hidrográfica do rio Zêzere (Fig. 1) e, pertence à sub-região administrativa do Médio Tejo. Tem como coordenadas geográficas WGS84: latitude - 39³4'32" N.; longitude $8^{\circ} 14$ ' 46" O. Altitude -267 metros ("Carta Militar de Portugal”, na escala 1: 25.000, fl. n. $\left.{ }^{\circ} 321\right)$.

A necrópole do Souto localiza-se na margem esquerda do rio Zêzere, à cota atual de $150 \mathrm{~m}$. Se nos reportarmos à Carta Militar de Portugal executada antes da construção da Barragem de Castelo de Bode, a cota seria de $50 \mathrm{~m}$; o que, do ponto de vista da visibilidade, a hidrologia pouco ou nenhum interesse teria para estas comunidades, que, muito provavelmente, se deslocariam pelas linhas de festo. Em termos geomorfológicos, esta área é classificada como tendo uma grande homo-

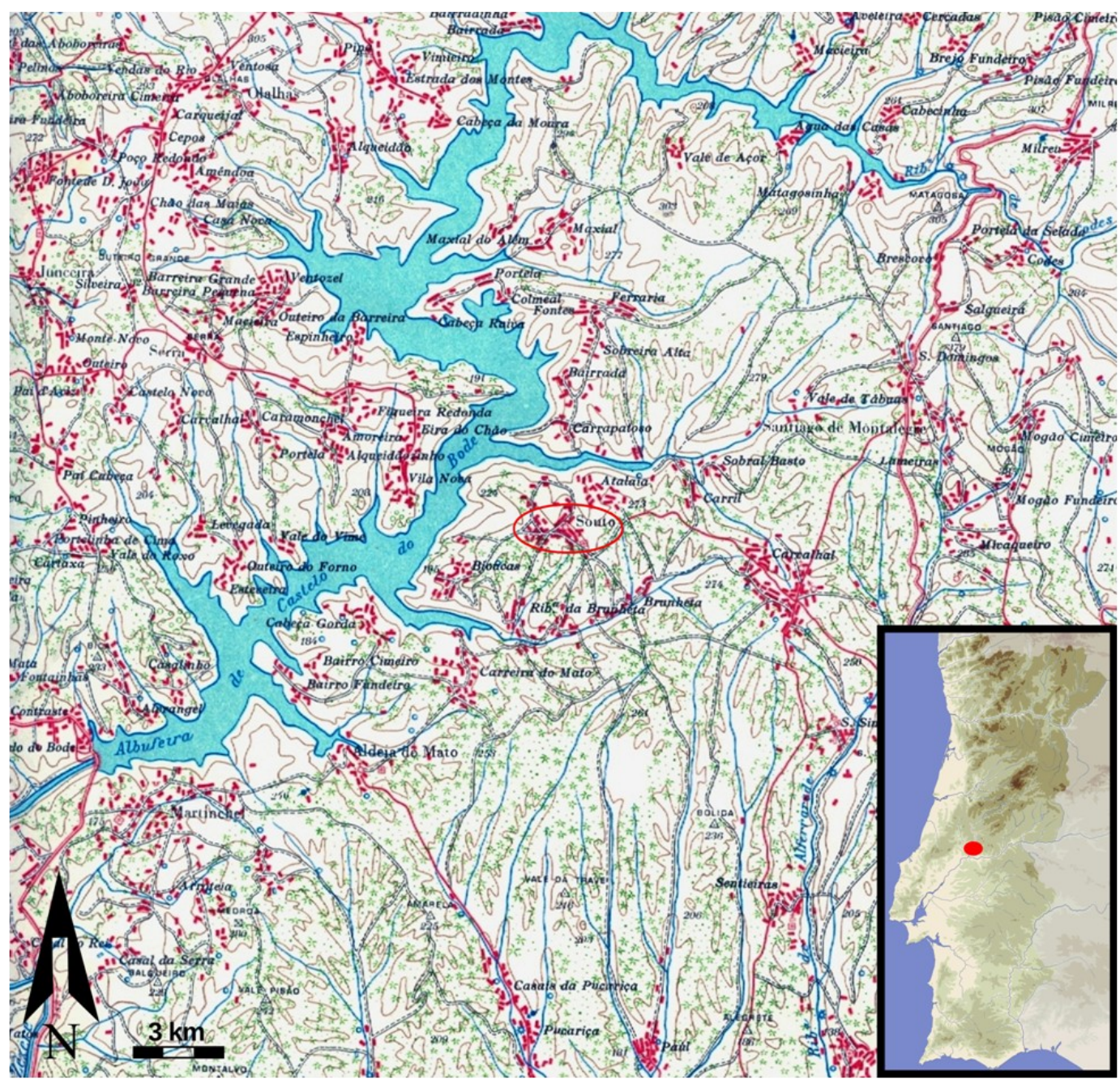

Fig. 1. Localização geográfica do Tumulus 1 do Souto no Portugal continental. Excerto da Carta Geográfica de Portugal (SGP), $\mathrm{n}^{\circ} 27$ (Tomar), escala 1: 100.000, 1988

Fig. 1. Geographic location of the Tumulus 1 of Souto in continental Portugal. Exert of the Geographic map of Portugal (SGP), $\mathrm{n}^{\circ}$ 27 (Tomar), scale 1: 100.000, 1988. 
geneidade em termos morfológicos e geológicos, onde as encostas são muito declivosas e a erosão é forte, litologias, geralmente detríticas e nem sempre consolidadas, ocorrem com frequência. Distribuem-se por conglomerados, arenitos, siltitos e argilas (SILvA, 2016: 48). O tumulus 1 do Souto está implantado em substrato atribuído ao Pliocénico (PA1 - conglomerados de Almeirim), podendo ocorrer esporadicamente sedimentos de cobertura do Miocénio (MT - argilas de Tomar), (Carta Geológica de Portugal, 1:50.000, fl. 27B).

Sobre este substrato foi construída uma couraça pétrea, constituída por clastos, blocos e seixos de quartzo e quartzito, e, ainda, alguns pequenos fragmentos de granito. A infiltração de sedimento pulverulento entre os vários constituintes pétreos do monumento revelou-se em perfil, como fazendo parte integrante da altimetria da própria couraça pétrea ( $-20 \mathrm{~cm}$ em profundidade). Este monumento possuía planta subcircular, com 6 metros de diâmetro (Fig.2).

A escavação do monumento permitiu a elaboração de uma proposta de reconstituição dos vários passos subjacentes à deposição dos restos humanos na grande urna, que se encontrava depositada na área central. Os restos humanos foram incinerados em local distinto e, tudo o indica, em conjunto com os materiais de bronze que fariam parte dos próprios adereços do morto. O estudo antropológico identificou a existência de um indivíduo, de sexo indeterminado, com idade compreendida entre os 16 e 20 anos (TOMÉ 2008).

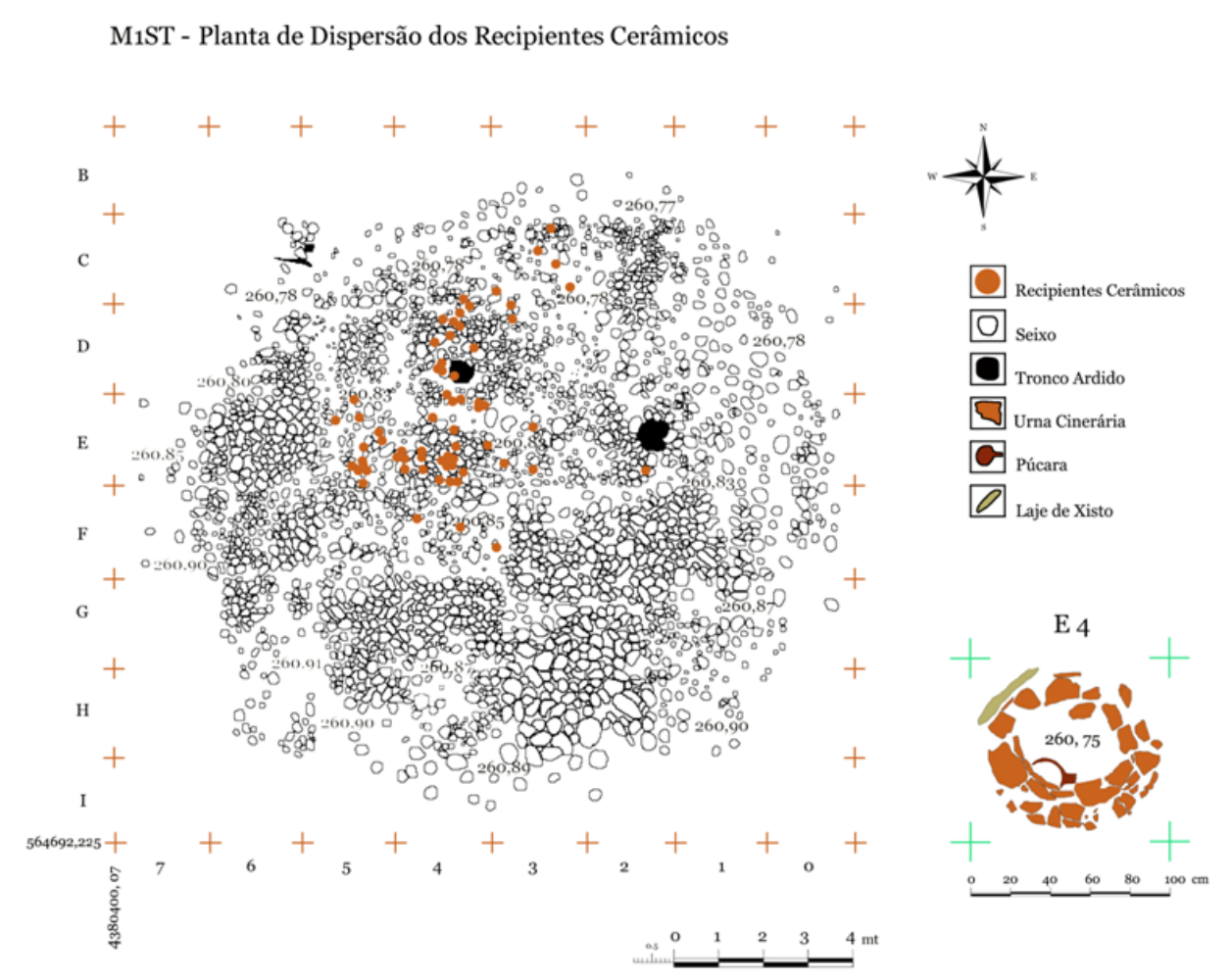

Fig. 2. Planta geral do tumulus 1 do Souto, com a deposição de recipientes cerâmicos já fragmentados, coeva da construção do tumulus. No lado direito, em baixo, apesenta-se pormenor da grande urna contendo o pequeno púcaro e adossada a um fragmento de xisto colocado na vertical Fonte: ANA CRUZ, 2010.

Fig. 2. General plant of the tumulus 1 of Souto, with the deposition of fragmented ceramic containers, coeval to the construction of the tumulus. On the right side, in the bottom, is presented a particular of the big urn with the small jar in the inside leaning to a schist stone fragment in vertical position. Source: CRUZ, 2010.

\section{MATERIAIS E CRONOLOGIA}

Os materiais arqueológicos foram principalmente encontrados dispersos pelo quadrante I e colocadas entre as fiadas de blocos. No contexto e objetivos do presente trabalho assumem especial interesse a grande urna e o púcaro de cerâmica e que se encontrava colocado verticalmente no interior daquela, logo no topo e de modo descentrado (Fig. 3-4A). A grande urna tem uma forma geomé- trica fechada que deriva do cone, com terminação recta a iniciar a base plana, colo e pança marcadamente separados, polimento brunido e sem decoração. Completo, embora com fissuras certamente resultantes da pressão das pequenas pedras que colmatavam o nível superior do enchimento, o pequeno púcaro apresenta perfil bicónico, bordo redondo de orientação direita, lábio arredondado, carena média, polimento brunido, pequeno colo sub-vertical e fundo côncavo. 

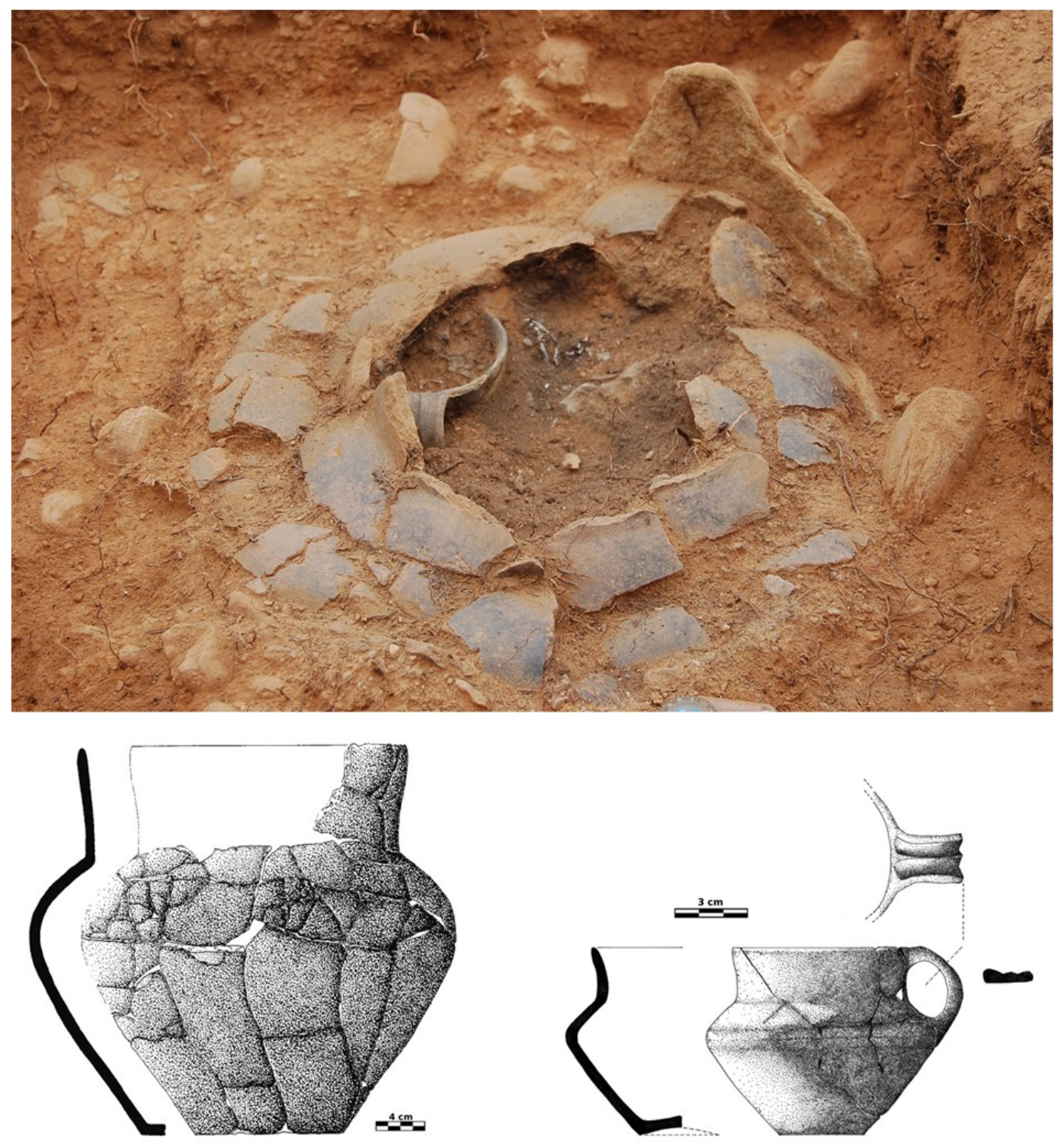

Fig. 3. Urna cinerária contendo pequeno púcaro carenado, adossada a um pequeno bétilo de xisto e imagens reconstruídas da urna (esquerda) e do púcaro (direita). CTA-IPT, 2008.

Fig. 3. Image off the cinerary urn containing a small jug attached to a small schist beetle on the top and the reconstructed draw of the urn (bottom left) and of the jug (bottom right). CTA-IPT, 2008.
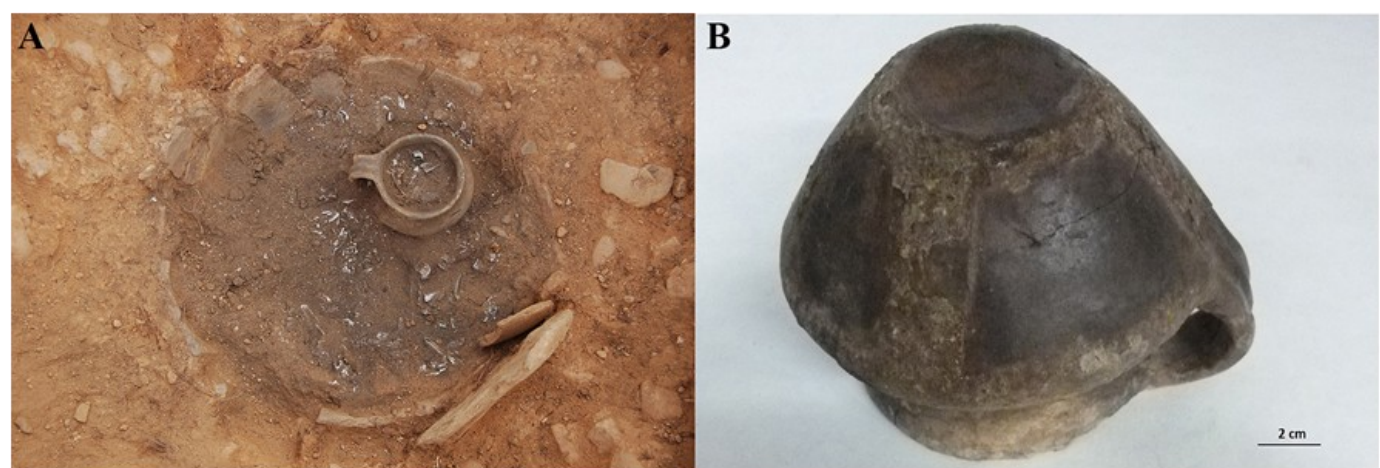

Fig. 4. Imagens do pequeno púcaro com fragmentos de ossos e de metal no interior da urna grande (A) e imagem do pequeno púcaro com bandas escuras (B).

Fig. 4. image of the small jug whit fragments of bone and metal inside the big urn (A) and image of the small jug with dark incrustation (B). 
O Tumulus 1 do Souto (Abrantes, Médio Tejo): Novos contributos para o conhecimento das materialidades do mundo funerário do Bronze Final no Centro de Portugal

Possui asa em fita, com marcada nervura central, que arranca do lábio e morre na linha de carena. Tem de altura $8 \mathrm{~cm}$ e de diâmetro de abertura 7,6 cm. Apresenta vestígios de desgaste permitindo supor uso intenso antes da sua deposição derradeira. $\mathrm{O}$ que o distingue de tantos outros recipientes semelhantes são as marcas que possui na superfície exterior.

Trata-se de um conjunto de quatro bandas planares (Fig. 4B), bastante regulares, dispostas verticalmente e de forma quase simétrica no bojo, em todo o seu redor, entre a carena e a base da peça, zonas onde também se evidenciam marcas idênticas. Aqui a largura das bandas varia entre $1 \mathrm{a}$ $1,5 \mathrm{~cm}$, sendo aquelas mais largas, entre os 2 e os $2,5 \mathrm{~cm}$. Por contraste com a superfície muito regular do corpo da peça, resultante do cuidado acabamento do seu fabrico, as zonas correspondentes às bandas revelam-se particularmente rugosas e irregulares, conferindo-lhes um tom mais claro.

Para além desta interessante peça cerâmica, os materiais de bronze recolhidos são igualmente de relevar, não obstante a sua extrema fragmentação. Atendendo às condições de jazida, os diversos fragmentos metálicos, que foram depositados juntamente com os restos ósseos, no interior da urna e do próprio púcaro (Fig. 4A), encontram-se também deformados na sequência da elevada temperatura a que estiveram sujeitos. As profundas transformações sofridas, com intensa fragmentação e deformação, condicionam qualquer interpretação segura quanto à identificação do(s) objeto(s) correspondente(s). Os distintos elementos que, no total, perfazem cerca de 350-400 gramas, demonstram a existência de quatro situações distintas (Fig. 5 A-B $-\mathrm{C}-\mathrm{D})$.
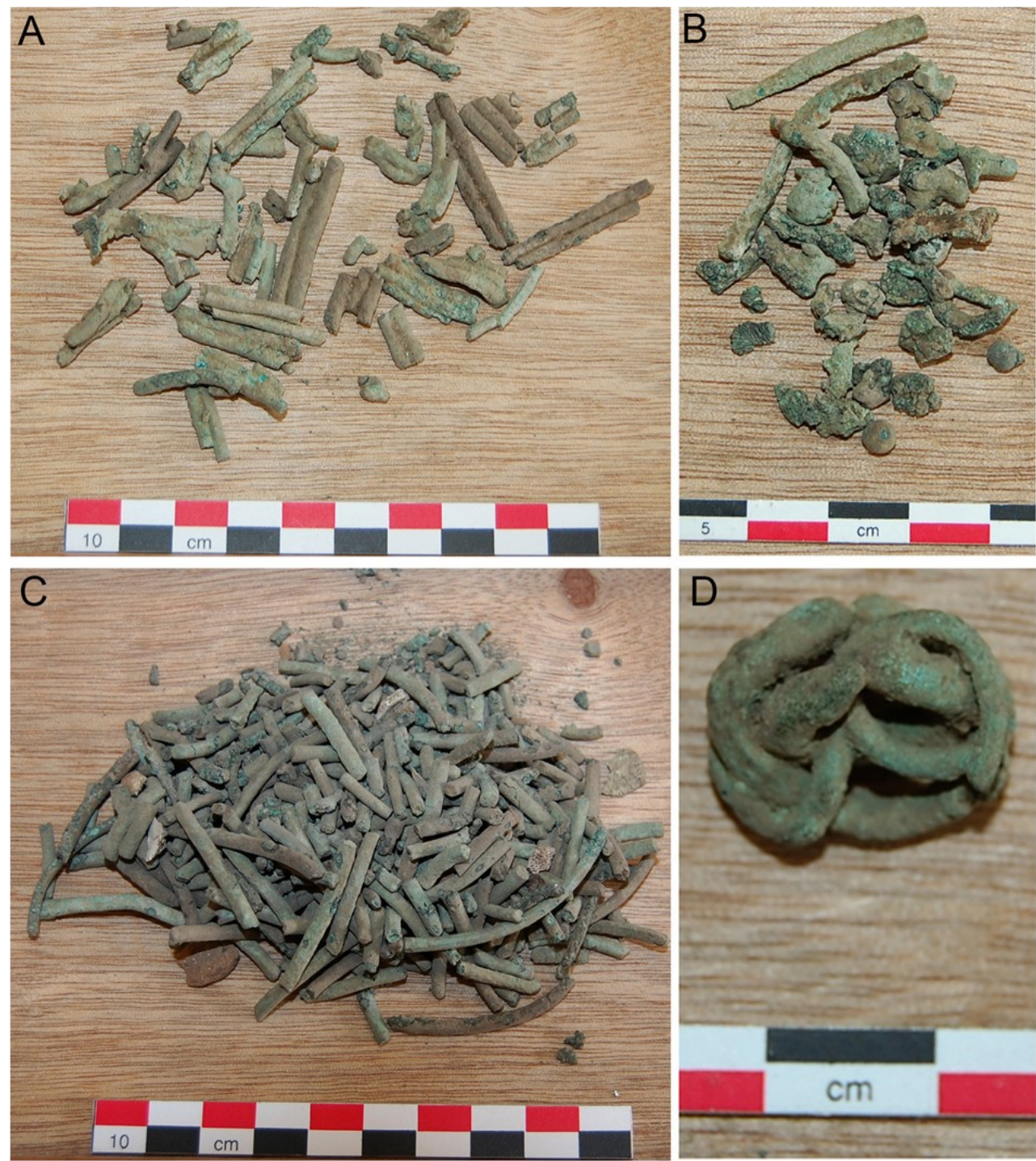

Fig. 5. Fragmentos metálicos recolhidos no interior da urna grande e do pequeno púcaro. A, fragmentos colados; $\mathrm{B}$, fragmentos irregulares e amorfos; $\mathrm{C}$, fragmentos de comprimento variável; $\mathrm{D}$, fragmento emaranhado.

Fig. 5. Metallic fragments recovered inside of the big urn and of the small jug. A, fragments sticked together; B, amorphous and irregular fragments; $\mathrm{C}$, fragments with different sizes; D, tangled fragment. 
$\mathrm{Na}$ sua esmagadora maioria trata-se de pequenos fragmentos de hastes subcirculares, de comprimento muito variável, por contraste com o diâmetro da secção, bastante regular, que oscila entre 3 e $5 \mathrm{~mm}$ (Fig. 5C). Alguns destes fragmentos encontram-se colados entre si (Fig. 5A), de modo aleatório, resultante do processo de incineração. Diferentes são os casos, muito raros, em que surgem não só colados, mas alinhados, associando dois e três troços de hastes. Contam-se depois alguns fragmentos irregulares e amorfos (Fig. 5B) e ainda, numa única situação, outro fragmento completamente emaranhado formando um nódulo, também resultante das elevadas temperaturas atingidas (Fig. 5D)

Estas evidências permitem admitir a possibilidade de corresponderem, pelo menos, a braceletes de tipo similar aos encontrados nos conjuntos de Alpiarça sugerindo uso simultâneo (VILAÇA et al. 1999: 22 e Est. II). Não só as evidências o indicam, como outros contextos crono-culturais similares fundamentam esta hipótese, sendo de referir, a propósito, o recente caso de El Molino de Abajo, em Villafranca de Los Barros (Extremadura, Espa- nha), com mais de 50 braceletes idênticos aos de Alpiarça (JIMÉNEZ ÁvILA \& GARCÍA CABEZAS 2014). Todavia, os dados revelam que não haveria apenas braceletes. Como bem se observa na figura 5 , alguns dos fragmentos de haste podem atingir cerca de $6 \mathrm{~cm}$ e outros (sendo certo que são pequenos fragmentos) não possuem qualquer indício de curvatura. Existiria, portanto, pelo menos mais uma outra peça distinta, de difícil identificação.

Do ponto vista cronológicos os materiais arqueológicos, especialmente cerâmicos, enquadram-se nas tipologias regionais do Bronze Final.

Para além dos critérios tipológicos dos materiais, que não oferecem dúvidas a nível cronológico, sobretudo a cerâmica, a cronologia deste monumento apoia-se ainda em duas datações de ${ }^{14}$ Carbono, obtidas por A.M.S., uma já publicada (CRUZ 2011), a outra até aqui inédita. Ambas foram obtidas a partir de ossos humanos, revelando, como seria de esperar, perfeita sintonia entre si (Tabela 1). Os resultados são indicativos de que a cremação do indivíduo poderá ter ocorrido entre finais do século XII a.C. e o século X a.C.

Tabela 1. Resultados obtidos da datação (A.M.S.) de três amostras de material osteológico. Os dados são reportados em RCYBP (idade de radiocarbono antes do presente, "presente"=AD 1950). Para a calibração da idade foi utilizada a base de dados IntCa104 (REIMER et al. 2004).

Table 1. Results obtained from the dating (A.M.S.) of two samples of osteologic material. Dates are reported as RCYBP (radiocarbon age before present, "present"=AD 1950. The calibration database IntCal04 was used for age calibration (REIMER et al. 2004).

\begin{tabular}{|c|c|c|c|c|}
\hline Laboratório & Idade BP & Idade Cal BP & Idade Cal BC a 2 sigma & Matéria-Prima \\
\hline Beta 463589 & $2810 \pm 30 \mathrm{BP}$ & $2999-2844$ & $1050-895$ & Ossos humanos \\
\hline Beta 450680 & $2850 \pm 30 \mathrm{BP}$ & $3060-2875$ & $1110-925$ & Ossos humanos \\
\hline Beta 450679 & $2840 \pm 40 \mathrm{BP}$ & $3070-2860$ & $1120-910$ & Ossos humanos \\
\hline
\end{tabular}

\section{MÉTODOS ANALÍTICOS}

Tendo como objetivo a caracterização arqueométrica dos materiais procedentes do Титиlus 1 do Souto, foram adotadas diversas técnicas analíticas consoante o tipo de material.

Quanto aos metais, perante a grande quantidade de pequenos fragmentos achados em escavação, foram aleatoriamente selecionados 4 fragmentos. Antes de serem analisados, procedeu-se à sua preparação mediante embutimento em resina e polimento, de modo a permitir que a análise química e a observação microscópica incidissem sobre o metal e não sobre a camada superficial de corrosão. A preparação das amostras e o ataque químico para a observação metalográfica foram realizados de acordo com o protocolo definido em SCOTT (1991).

$\mathrm{O}$ estudo arqueométrico realizado sobre os metais teve os seguintes objetivos: a) determinar a composição elementar dos metais encontrados na sepultura mediante fluorescência de Raios-X portátil (pXRF), b) identificar a presença de pequenas inclusões metálicas por microscopia electrónica de varrimento com espectrómetro de raios-X por dispersão de energias (SEM-EDS); c) definir a microestrutura dos metais, de forma a se identificar a cadeia operatória aplicada na sua produção (mediante microscopia óptica de reflexão).

As bandas identificadas no pequeno púcaro foram inicialmente analisadas de forma nãodestrutiva mediante $\mathrm{pXRF}$, obtendo-se dados qualitativos da composição elementar das incrustações em 4 pontos diferentes (1-base, 1-carena, 2- banda do bojo). Nos mesmos pontos, previamente analisados por pXRF foram retiradas pequenas quantidades de material para efetuar o estudo mineralógico por $\mu$ XRD e micro-estrutural (SEM-EDS). O objetivo desta abordagem foi determinar a natureza das incrustações para complementar o estudo arqueológico e tipológico da peça. 
No que diz respeito à análise da cerâmica, procedeu-se ao estudo da urna cinerária de maiores dimensões. O estudo arqueométrico da cerâmica teve como objetivos: a) determinar as características da matéria-prima utilizada; b) a tecnologia de produção; c) a compatibilidade (ou não) da matéria -prima utilizada no fabrico da urna com a geologia da região. Por isso, adaptou-se a metodologia clássica para caraterização dos materiais cerâmicos que incluem a preparação, e estudo, de uma lâmina delgada com um microscópio petrográfico, a análise mineralógica por difração do raios- $\mathrm{X}$ de um pequeno fragmento de amostra reduzido em pó e a caraterização micro-estrutural da matriz de argila e das inclusões por SEM-EDS.

\subsection{Fluorescência Portátil de Raios-X (pXRF)}

A determinação da composição elementar de 4 fragmentos metálicos selecionados e das incrustações foi efetuada através de um espectrómetro portátil de fluorescência de raios-X, modelo Bruker Tracer III-SD equipado com um tubo de Raios X de Ródio (Rh) e com um detector SDD X-Flash ${ }^{\circledR}$, com uma resolução de $145 \mathrm{eV}$ no linha $\mathrm{K} \alpha$ do $\mathrm{Mn}$. As análises foram realizadas com as seguintes condições de trabalho: tempo de aquisição 60 segundos; 40 $\mathrm{KV}, 12.5 \mu \mathrm{A}$; filtros de $\mathrm{Al} / \mathrm{Ti}(304.8 \mu \mathrm{m}$ alumínio/25.4 $\mu \mathrm{m}$ titânio). Os espectros foram adquiridos com o software Brüker S1PXRF v.3.8.30 e tratados com o software Brüker ARTAX v.5.3.0.0. A quantificação dos elementos químicos foi realizada com padrões de referência com uma composição semelhante aos materiais analisados, tendo sido utilizados os padrões BCR-691 (INGELBRECHT et al. 2001).

\subsection{SEM-EDS}

Esta técnica analítica, adotada quer para os metais, quer para a lâmina delgada elaborada a partir do fragmento da urna maior e nas incrustações encontradas no púcaro, foi realizada através de um microscópio de varrimento de pressão variável HITACHI S-3700N equipado com espectrómetro de raios-X por dispersão de energias Bruker Xflash Silicon Drift Detector (SDD). A adquisição dos dados foi realizada através do software Brüker Esprit v.1.9. Duas condições de análises diferentes foram adaptadas para os metais e as incrustações $(20 \mathrm{KeV}, 120 \mathrm{~mA},<1 \mathrm{~Pa})$ e para a análise da cerâmica $(20 \mathrm{KeV}, 120 \mathrm{~mA}, 40 \mathrm{~Pa})$.

\subsection{Microscopia óptica a luz refletida e transmitida \\ O estudo por microscopia óptica foi realizado nos metais e na cerâmica. A observação metalográ-}

fica teve por objetivo determinar a microestrutura dos fragmentos metálicos, o que permitiu reconstruir a cadeia operatória aplicada na sua produção. $\mathrm{O}$ estudo petrográfico sobre a cerâmica permitiu descrever a mineralogia, a presença de fragmentos de rochas, a porosidade, a matriz e a presença de possíveis tratamentos superficiais. A percentagem de inclusões, o grau de arredondamento e as suas dimensões médias foram definidas de acordo com as tabelas de referência publicadas em ORTON \& HuGHES 2013.

Para o estudo microscópico foi utilizado um equipamento modelo Leica DM-2500-P, com uma câmara modelo Leica MC-170-HD.

\subsection{Difração dos Raios-X (XRD)}

Recorreu-se à difração de raios-X (XRD) de amostras orientadas para o estudo mineralógico da cerâmica; a amostra foi previamente moída num almofariz de ágata. O mesmo equipamento, em modalidade $\mu \mathrm{XRD}$ foi também utilizado para determinar a natureza das incrustações encontradas no púcaro. O equipamento utilizado foi um difratómetro Bruker D8 Discover, com sistema Da Vinci. A análise mineralógica foi efetuada entre os 3 e os $75^{\circ}$ em $2 \theta$, com passo de $0.05^{\circ}$ e um período de aquisição de 1 segundo por passo. Os resultados foram interpretados com o programa Diffract-Eva utilizando a base de dados PDF2.

\section{RESULTADOS, INTERPRETAÇÃO E DISCUSSÃO}

\subsection{Metais}

De acordo com os resultados da análise elementar por pXRF (Tabela 2), os fragmentos metálicos analisados indicam que estamos perante ligas de bronze $(\mathrm{Cu}+\mathrm{Sn})$, com presença relativamente reduzida de elementos secundários, nomeadamente arsénio (As), prata (Ag) e ferro (Fe), com um valor total que não ultrapassa $0.5 \mathrm{wt} \%$. Relativamente à presença destes elementos, contudo, convém recordar que o metal, devido à espessa camada de corrosão, não ficou completamente limpo, o que poderá ter tido alguma influência na quantificação.

De facto, as análises realizadas por espetros copia de raios por dispersão em energia (EDS) em áreas mais circunscritas, cujos limites foram controlados por imagens obtidas no SEM, sugerem que os fragmentos metálicos — completamente limpos de qualquer produto de alteração - sejam compostos por cobre e estanho, cujo valor não ultrapassa, nas várias áreas analisadas, 15.0 wt.\% $\mathrm{Sn}$. O próprio valor do estanho obtido por pXRF, tendencialmente mais elevado do que nas análises 
Tabela 2. Resultados obtidos por espetroscopia pXRF.

Table 2. results obtained by pXRF spectroscopy

\begin{tabular}{|c|c|c|c|c|c|}
\hline & Cu (wt.\%) & Sn (wt.\%) & As (wt.\%) & Ag (wt.\%) & Fe (wt.\%) \\
\hline Fragmento 1 & 79.9 & 19.7 & 0.3 & $<0.05$ & 0.13 \\
\hline Fragmento 2 & 81.2 & 18.6 & 0.1 & $<0.05$ & 0.09 \\
\hline Fragmento 3 & 81.7 & 18.0 & 0.14 & $<0.05$ & 0.12 \\
\hline Fragmento 4 & 79.0 & 20.6 & 0.28 & $<0.05$ & 0.11 \\
\hline
\end{tabular}

realizadas com o SEM-EDS, parece sugerir que os dados da tabela 2 poderão estar de facto influenciados por fenómenos de enriquecimento ocorridos na camada de alteração superficial dos artefactos (RoBBiola et al. 1998).

Ainda através do SEM-EDS foi possível confirmar a presença de pequenas inclusões enriquecidas em Ag (Fig. 6A), cuja presença vestigial também foi comprovada pelas análises de pXRF. Finalmente, a observação por microscópio óptico permitiu identificar uma estrutura dendrítica, típica dos metais que não sofreram qualquer tipo de tratamento pós-fundição (Fig. 6B). Esta circunstância sugere que a forma final das peças metálicas terá sido dada pelo molde de fundição e não por trabalhos de forja e recozimento das peças. Os dados obtidos sobre os fragmentos procedentes do Tumulus 1 do Souto enquadram-se numa tradição metalúrgica recorrente no Bronze Final do Centro de Portugal, caracterizada pela ocorrência de ligas de bronze $(\mathrm{Cu}+\mathrm{Sn})$ com uma presença relativamente diminuta de elementos secundários. Estes dados ocorrem tanto em povoados (VILAÇA 1997; CANHA et al. 2007; VILAÇA et al. 2012), como em depósitos (GUTIÉRREZ NEIRA et al. 2011; BotTAINI et al. 2012; BOTTAINI et al. 2016), o que aponta para a transversalidade deste tipo de metalurgia nos diversos contextos arqueológicos. Por outro lado, convém notar que a presença de metais em contextos funerários é um facto pouco usual no Bronze Final do Centro de Portugal. Embora as informações sobre as estratigrafias e os contextos de proveniência nem sempre sejam suficientemente claras, devido à casualidade da esmagadora maioria dos achados, merecem ser mencionadas, até pelo enquadramento geográfico de grande proximidade, na região de Alpiarça, as sepulturas de Meijão, de Tanchoal dos Patudos (VILAÇA et al. 1999) e do Cabeço da Bruxa (KALB \& HocK 1981), caracterizados pela presença de um espólio composto por braceletes metálicos. O espólio metálico do Tumulus 1 do Souto confirma assim um dado já discutido em Vilaça et al. 1999, isto é, o da seleção tipológica dos artefactos metálicos que acompanham as sepulturas. Apesar da indefinição tipológica/funcional dos metais analisados, o espólio do Tumulus 1 de Souto confirma que determinados tipos de artefactos (i.e. machados, foices, espadas, punhais, etc.) não são selecionados para acom- panhar a sepultura do defunto, sendo antes depositados em contextos de outra natureza. De todo o modo, os dados analíticos apresentados revelam uma estreita afinidade tecnológica entre aqueles metais - ligas binárias com baixos conteúdos de elementos secundários - e os demais conhecidos para o Bronze Final do Centro de Portugal. Esta situação parece sugerir que não haveria qualquer tipo de diferenciação - ao nível de tecnologia de fabrico - entre objetos produzidos para as actividades do quotidiano ou para situações excepcionais, nomeadamente em contextos funerários.
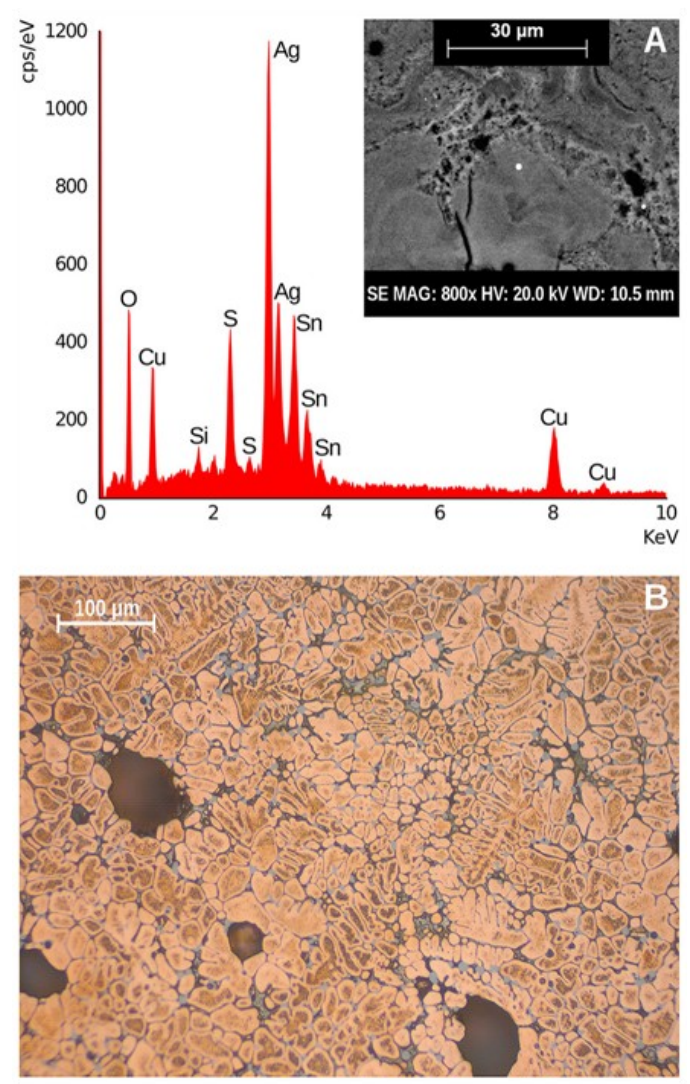

Fig. 6: A) Imagem de microscópio eletrónico relativo à presença de pequenas inclusões globulares (de cor branca na figura) ricas em $\mathrm{Ag}$; B) microestrutura de um dos fragmentos por microscopia óptica.

Fig. 6: A) Scanning microscopy image of a small globular inclusion (white in the picture) enriched in $\mathrm{Ag}$; B) microstructure of one of the fragments by optical microscopy. 
O Tumulus 1 do Souto (Abrantes, Médio Tejo): Novos contributos para o conhecimento das materialidades do mundo funerário do Bronze Final no Centro de Portugal

\subsection{Bandas com incrustações do pequeno púcaro}

O estudo efetuado por XRF portátil no púcaro, em concreto nos 4 pontos previamente mencionados, evidenciou a presença de elementos químicos menores contaminantes a partir do solo ou ligados à matéria-prima usada na peça, como $\mathrm{Al}$, $\mathrm{Si}, \mathrm{P}, \mathrm{S}, \mathrm{Ti}, \mathrm{Ca}, \mathrm{K}, \mathrm{Hg}, \mathrm{Mn}, \mathrm{Fe}, \mathrm{Sr}, \mathrm{Zr}, \mathrm{Rb}$, e de elementos químicos como $\mathrm{Sn}, \mathrm{Cu}, \mathrm{Zn}$ e As (Fig. 7), em concentração superior.
Estes primeiros dados foram complementados também com o estudo, por $\mu$ XRD (Fig. 8), de 4 micro amostras com a identificação de fases mineralógicas como cassiterite (muito abundante), cuprite e tenorite (em quantidade menor). Foi também encontrado ciclo tetrafosfato de cobre.

A análise micro-estrutural efetuada por SEMEDS num dos fragmentos retirado das bandas escuras na superfície do púcaro (Fig. 9) revelou elevada concentração de estanho, confirmando os dados recolhidos por $\mathrm{pXRF}$ e $\mu \mathrm{XRD}$.

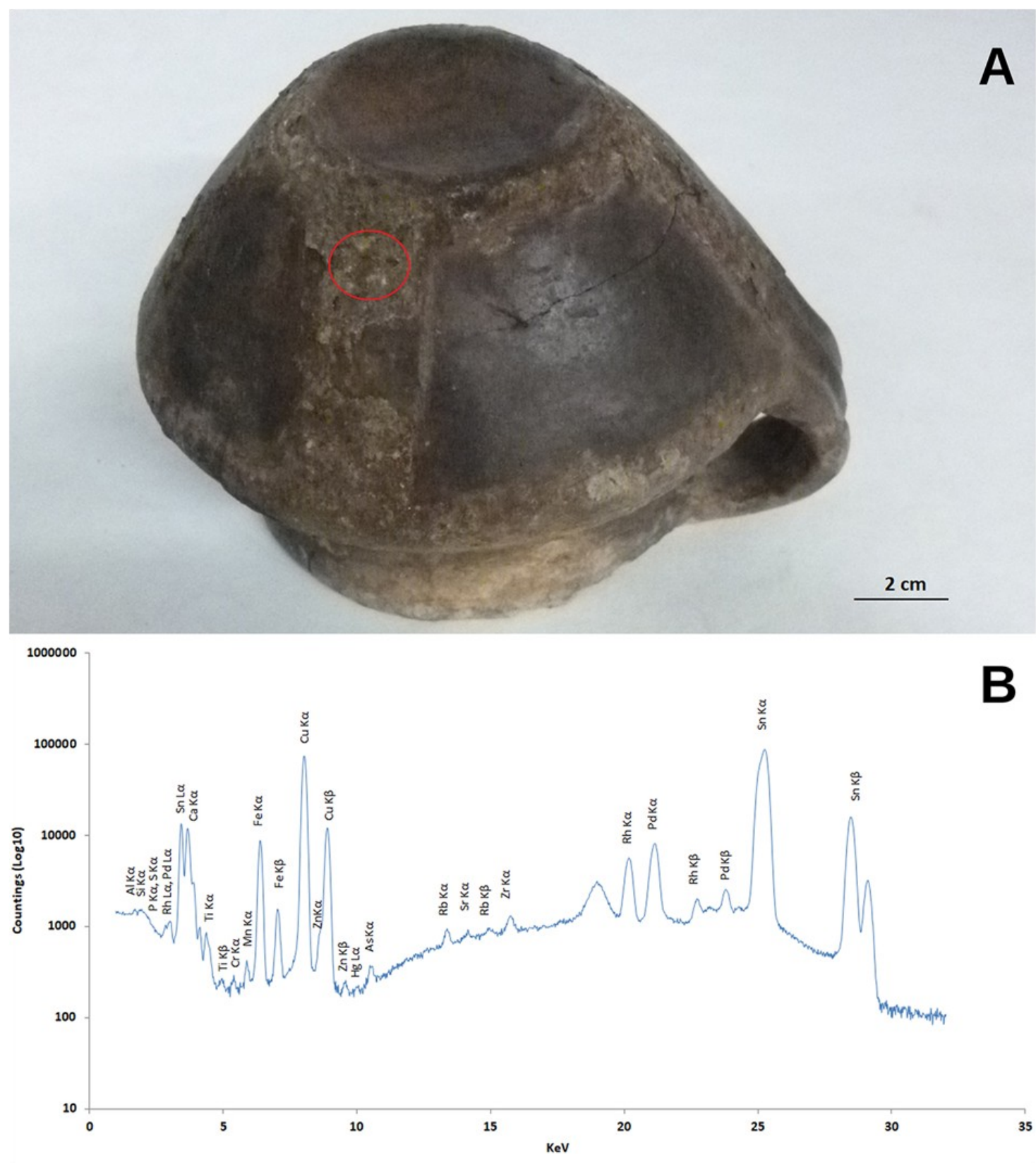

Fig. 7. Imagens do pequeno púcaro com as incrustações com identificação do ponto analisado por fluorescência de Raios X portátil (A) e espetro em escala logarítmica com indicação dos elementos químicos identificados (B).

Fig. 7. Image of the small jug the incrustations and identification of one of the points analysed by portable XRF spectroscopy (A) and spectrum in logarithmic scale whit the chemical elements identified (B) 


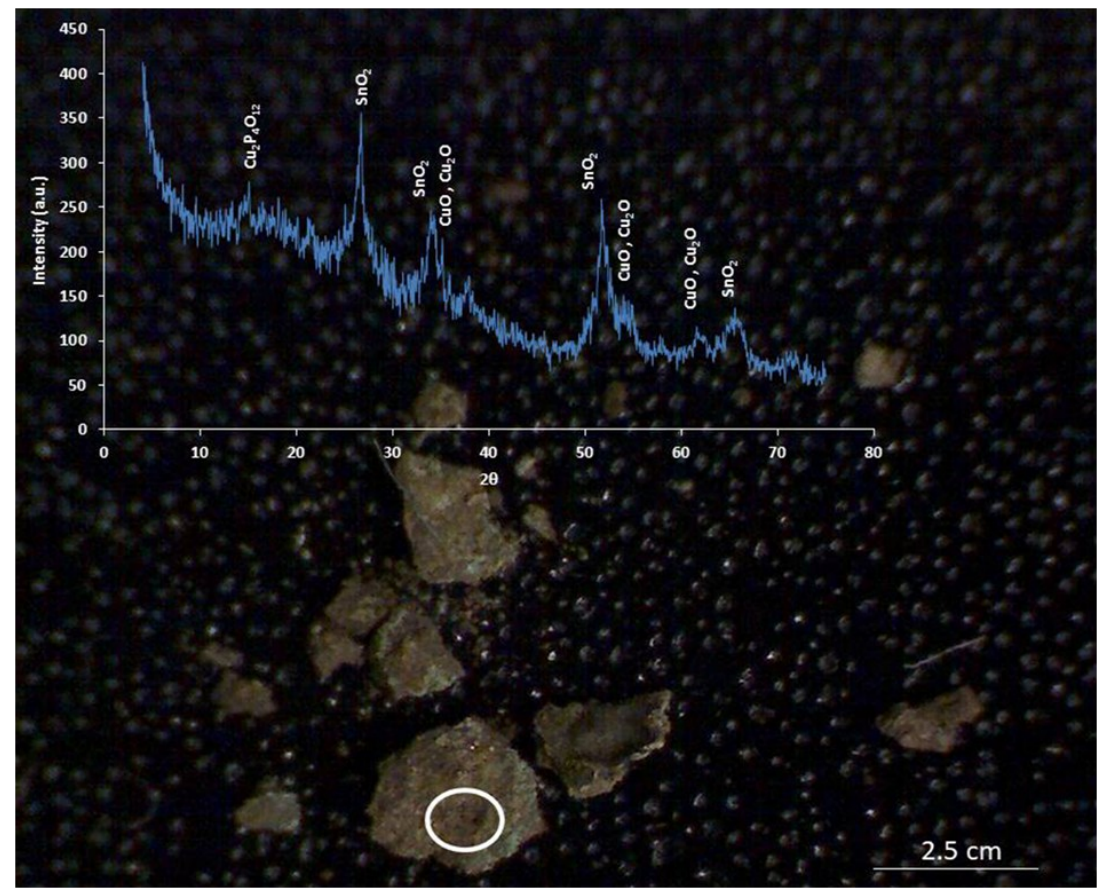

Fig. 8. Pequenos fragmentos de material retirado mecanicamente da superfície do pequeno púcaro e espetro obtidos por micro-difração de raios X com a identificação dos principais compostos identificados.

Fig. 8. Small fragments of material sampled from the surface of the small jug and spectra obtained by micro $\mathrm{X}$ ray diffraction whit the identification of the main mineralogical phases.

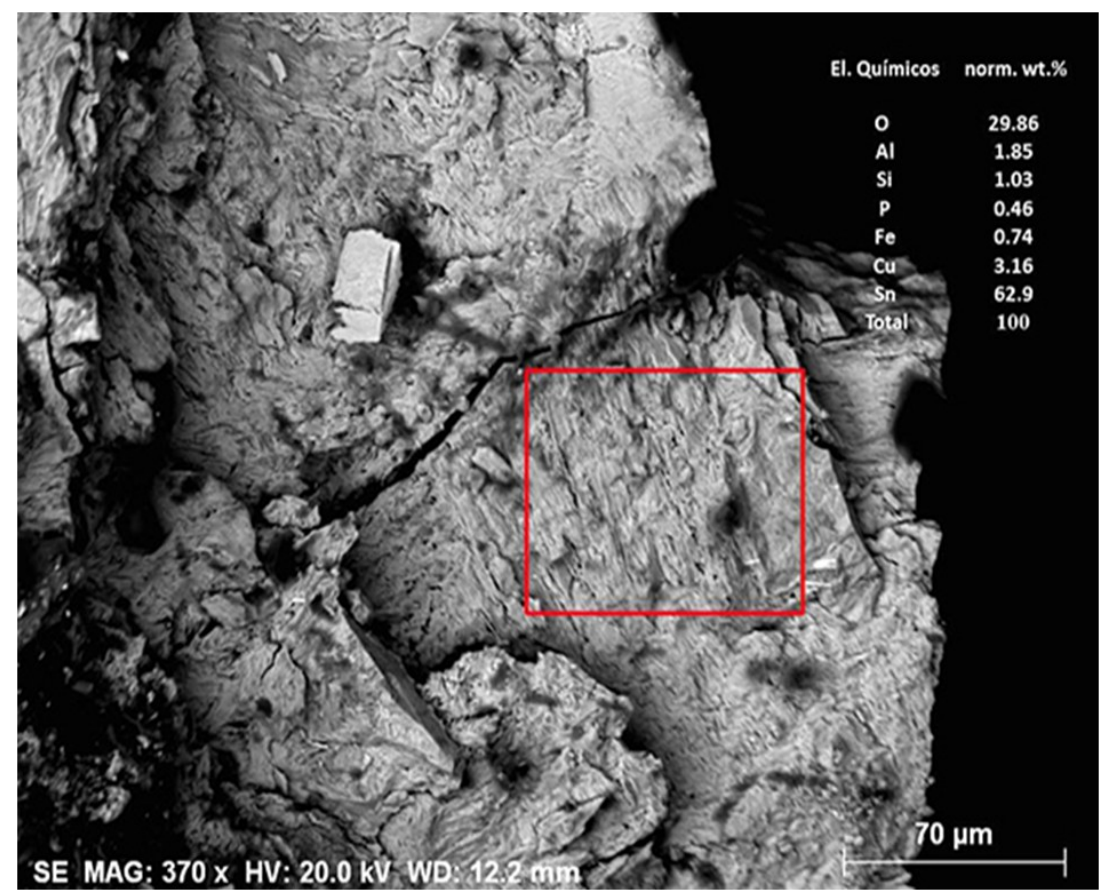

Figura 9: Imagem obtida ao microscópio eletrónico de varrimento de um pequeno fragmento de material retirado mecanicamente da superfície da pequena púcaro com análise química anexa.

Figure 9: Image obtained on the scanning electron microscope of a small fragment $f$ incrustation sampled from the surface of the small jug whit chemical analysis annexed. 
Estanho e cobre são os elementos químicos principais identificados nas bandas escuras observadas na superfície do pequeno púcaro. Normalmente a presença destes elementos químicos em concentrações elevadas podem ser relacionadas com a presença de uma liga metálica. Também as características do contexto arqueológico, com materiais metálicos no interior da grande urna e do pequena púcaro, não explicam a concentração elevada destes dois elementos químicos em áreas perfeitamente delimitadas na superfície do púcaro. $\mathrm{O}$ enriquecimento de estanho $(62.9 \mathrm{wt} \%)$, se comparado com o cobre (3.16 $\mathrm{wt} \%)$, sugere que as bandas escuras podem ser "pátina", ou seja produtos de alteração, de uma liga metálica de bronze composta por cobre e estanho (RoBBIOLA et al. 1998, COSTANTINIDES et al. 2002, WADSAK et al. 2000, INGO et al. 2004, INGO et al. 2006, SCOTT 1985), ou uma liga muito enriquecida em estanho que ficou em contacto com a superfície do pequeno púcaro como descrito em outros contextos arqueológicos (CORDIER 1975: 464, MAITY et al. 2013: 106). A presença de tetrafosfato de cobre pode ser explicada com a presença de uma grande quantidade de material osteológico no mesmo contexto arqueológico.

O estudo desta peça constitui enorme desafio que importará aprofundar futuramente, colocandose aqui algumas hipóteses exploratórias. Se forma e fabrico são perfeitamente banais para a época e região, já as marcas em banda que possui na superfície exterior são completamente inusuais. A sua regularidade e posicionamento afastam por completo qualquer hipótese de terem resultado de processos pós-deposicionais aleatórios. Pelo contrário, o seu aspeto permite pensar na hipótese de terem resultado da aplicação de algum tipo de material sobre a linha da carena, a linha da base e em quatro bandas perpendiculares àquelas. Nessa hipótese, o material poderia ter estado não só em contacto, mas ter sido fixado, inclusive com recurso a algum tipo de substância usada como ligante, resina, ou outro. Esse material, que as análises revelaram corresponder a uma liga de cobre com elevado teor de estanho, ter-se-ia descolado depois, deixando as marcas que se observam, como se fossem incrustações. Esta leitura é condizente com a hipótese de se tratar de uma solução com finalidade decorativa, com recurso à aplicação de elementos de bronze, no caso bandas, na superfície do vaso. A elevada percentagem de estanho, que tornaria o bronze mais brando, estaria em sintonia com esse objetivo, tornando mais fácil a sua aplicação. Em alternativa, coloca-se a hipótese de essas marcas testemunharem o desgaste resultante do contacto do recipiente com um outro corpo distinto, por exemplo um suporte externo, metálico. Nesta hipótese, o uso de eventual suporte onde o recipiente assentaria não descarta liminarmente o recurso a substância aderente para auxiliar a sua fixação, acomodando-o melhor. Se esta hipótese se confirmasse, não seria despropositado considerar que entre os fragmentos de bronze depositados existissem restos desse suporte, o qual teria sido assim também alvo de destruição pelo fogo. Em todo o caso, os resultados analíticos obtidos nada comprovam a este respeito. Numa ou noutra hipótese, a verdade é que se trata de uma situação excecional, para a qual não conhecemos paralelos. É certo que a decoração de cerâmica do Bronze Final com incorporação de elementos metálicos não é inédita, embora muito rara, e, de resto, insuficientemente estudada. Nem alémPirenéus, onde se destacam as cerâmicas do Bronze final francês, nomeadamente do Centro-Oeste e sobretudo da região dos lagos alpinos, ornamentadas com delicadas lamelas de estanho (sempre muito mais finas e em regra associadas a pintura), nem mesmo na Península Ibérica (Meseta, Extremadura, Andaluzia), onde são conhecidos alguns, raros, exemplares decorados com pequenas incrustações metálicas, encontramos situações comparáveis ao que se observa no púcaro de Souto 1 . O próprio metal utilizado é diferente, contando-se aplicações de estanho puro, como foi revelado no estudo do prato de La Jardelle (Dissay, Vienne) (MAITY et al. 2013: 106), ou de ligas de cobre onde o estanho ocorre enquanto elemento principal, como sucedeu na famosa urna de Sublaines (Indre-et-Loire) (CORDIER 1975: 464) e igualmente no púcaro em análise. $\mathrm{O}$ estudo das cerâmicas com decoração metálica necessita de ser aprofundado, designadamente em termos tecnológicos, e o caso presente constitui incentivo a não perder de vista problemática tão desafiante. Tal como não deverá ser negligenciada pesquisa futura sobre a questão dos suportes metálicos em contextos ocidentais do Bronze Final.

\subsection{Urna cinerária}

As observações realizadas em lâmina delgada permitiram determinar as características da matéria -prima utilizada na preparação da grande urna cinerária. A amostra é composta por uma matriz com porosidade concentrada na parte central da lâmina delgada (Fig. 10 A, B). Os óxidos, opacos, são constituídos principalmente por ilmenite (ver também análise pontual efetuada por SEM-EDS). Na zona lateral da lâmina delgada (superfície exterior da urna) a granulometria das inclusões diminui devido ao tratamento da superfície por alisamento. O desengordurante, com forma angular e subarredondado, é mediamente depurado, apresentando uma granulometria dispersa até aos $2 \mathrm{~mm}$ e uma presença de inclusões com $20 \%$ do volume do material. Foram identificados os minerais quartzo, plagióclase, anfíbolas, biotite, em quantidades mais reduzidas, feldspatos de potássio. Foram ainda 


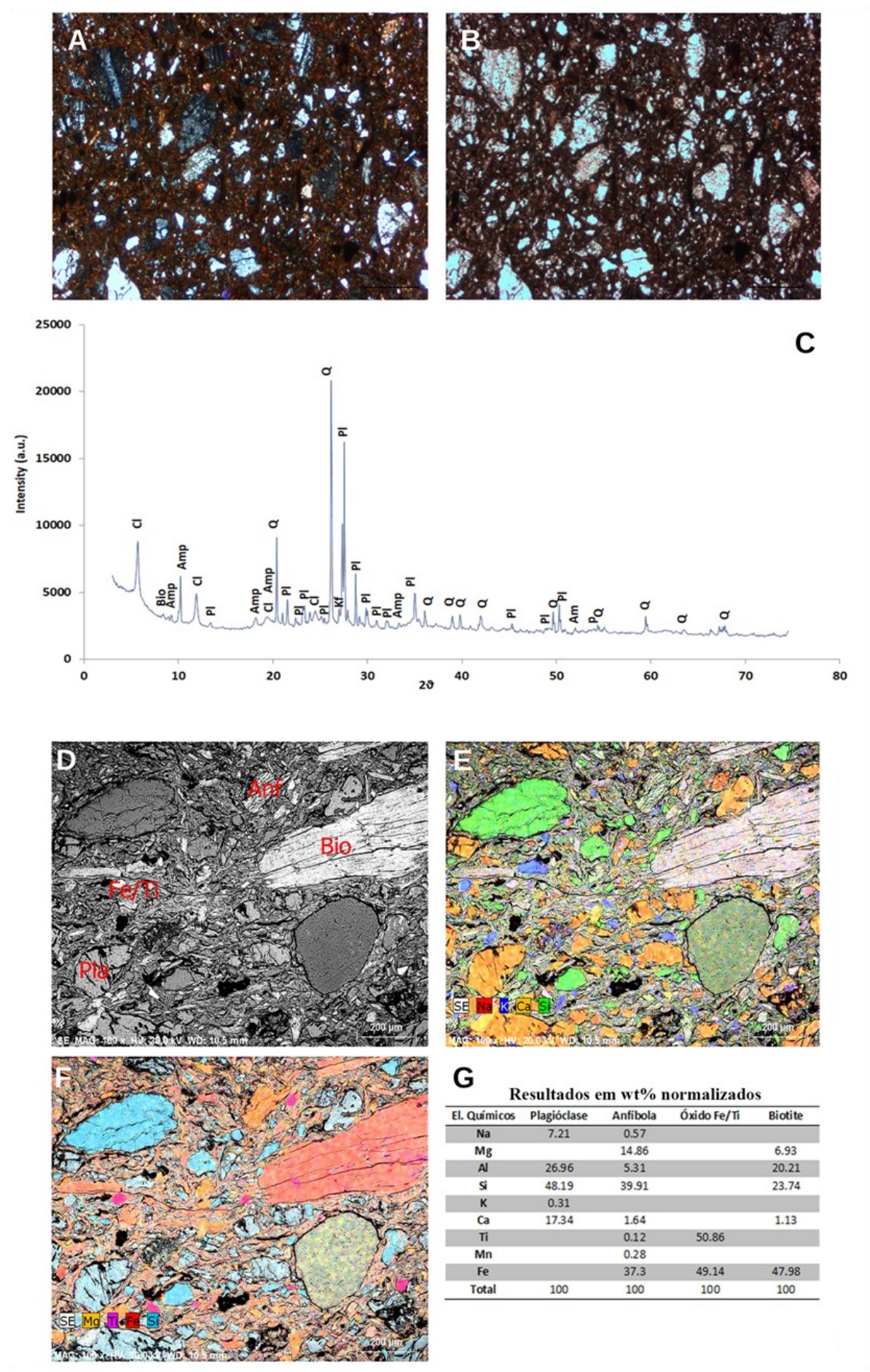

Fig. 10. Estudo petrográfico da grande urna A) nicóis cruzados, B) nicóis paralelos; C) estudo mineralógico por difração de Raios $\mathrm{X}(\mathrm{C}, \mathrm{Clo}=$ Clorita, $\mathrm{Bio}=$ Biotita, $\mathrm{Pla}=$ Plagioclásio, $\mathrm{Q}=$ Quartzo, $\mathrm{Kf}=$ Feldspato de Potássio, Amp = Anfíbola); D) imagem obtida no estudo ao microscópio eletrónico de varrimento com a identificação de algumas espécies mineralógicas; E) mapa composicional que evidencia a distribuição do $\mathrm{Na}, \mathrm{K}, \mathrm{Ca}, \mathrm{Si}$; F) mapa composicional que evidencia a distribuição do $\mathrm{Mg}, \mathrm{Ti}, \mathrm{Fe}, \mathrm{Si}$; $)$ resultados das análises pontuais efetuadas nos cristais identificados na figura 10D (resultados apresentados em percentagem em peso, wt $\%$, normalizados a $100 \%$ ).

Fig. 10. Petrographic study of the big urn A) parallel nichols, B) crossed nichols; C) mineralogical study by $X$ ray diffraction $(\mathrm{C}, \mathrm{Clo}=$ Clorite, $\mathrm{Bio}=$ Biotite, $\mathrm{Pla}=$ Plagioclase, $\mathrm{Q}=$ Quartz, $\mathrm{Kf}=$ Potassium Feldspar, $\mathrm{Amp}=$ Amphibole); D) image obtained at the scanning electron microscope whit the identification of some mineralogical species; E) compositional distribution map of do $\mathrm{Na}, \mathrm{K}, \mathrm{Ca}, \mathrm{Si}$; F) compositional distribution map of $\mathrm{Mg}$, $\mathrm{Ti}$, $\mathrm{Fe}, \mathrm{Si} ; \mathrm{G}$ ) results of the chemical analyses performed on the minerals of figure 10D (results presented in weight percentage, wt $\%$, normalized to $100 \%$ ) . 
identificados fragmentos de rocha metamórfica com quartzito, xisto, gnaisse e anfibolito.

As análises por difração dos raios-X (Fig. 10 C) confirmaram as observações realizadas ao microscópio petrográfico, permitindo identificar, a partir das espécies mineralógicas mais abundantes, quartzo, plagióclase, anfíbola, clorite, biotite e feldspato potássico. A presença de minerais da argila como a clorite aponta para temperaturas de cozedura inferiores ao $600^{\circ} \mathrm{C}$ (MARITAN et al. 2006, MAGGETTI et al. 2011). As análises por SEM -EDS (Fig. 10 D, E, F, G) tiveram como objetivo determinar a distribuição dos elementos químicos maiores (especialmente do $\mathrm{Na}, \mathrm{K}, \mathrm{Ca}, \mathrm{Mg}, \mathrm{Al}, \mathrm{Si}$, $\mathrm{P}, \mathrm{Fe}, \mathrm{Ti}$,) e determinar a composição química dos feldspatos e das anfíbolas. Os resultados permitem identificar a presença de labradorite, com base na proporção entre albite e anortite obtida por SEMEDS, e de anfíbolas pobres em Ca e enriquecida em $\mathrm{Fe}$ (provavelmente, cummingonite). Foram também identificados biotite e óxidos de Fe-Ti (ilmentite). Do ponto de vista tecnológico, o grau de arredondamento dos grãos, na maior parte com forma angular e sub-angular, sugere que a urna tenha sido realizada com recurso a sedimentos com transporte curto. Considerando as características mineralógicas observadas, encontram-se semelhanças com o Complexo Ígneo Máfico de Mouriscas (HENRIQUeS et al. 2015), localizado em direção SE em relação ao Souto 1 e composto sobretudo por anfibolito. A presença de fragmentos de rocha metamórfica como quartzite e gnaisse não exclui a utilização de materiais procedentes da alteração de anfibolitos e gnaisse anfibolíticos presentes no Complexo do Sardoal, onde se encontram intercalados por orto-gneiss, especialmente na zona do Cabeço de Moura, Amoreira e Vale das Vacas. Os dados obtidos sobre a urna cinerária tornam plausível a utilização de matérias-primas locais, possivelmente procederem de um raio de até $10-15 \mathrm{~km}$ do sítio arqueológicos, utilizando-se produtos de alteração das rochas previamente mencionada.

\section{A SEPULTURA DE SOUTO 1 NO QUA- DRO REGIONAL}

O pequeno Tumulus 1 de Souto corresponde a uma sepultura de incineração individual em urna datável de finais da Idade do Bronze e íntegra uma necrópole de cinco (cf.) tumuli ainda insuficientemente caracterizada no seu conjunto e em termos monográficos, projeto em curso de um dos autores (a.C.). Por isso, será prematuro desenvolver neste momento maiores considerações sobre esta interessante necrópole. Com um longo passado a nível europeu, se bem que difuso e pouco expressivo até inícios da Idade do Bronze (v.g. HARDING 2003), o ritual de incineração poderá ter sido adotado por determinadas comunidades do Centro do território português mais ou menos por essa altura. Todavia, será só com o II milénio a. C. já avançado, e particularmente no seu final e no alvorecer do milénio seguinte, que este ritual deixará rasto, como testemunham, entre outros (cf. adiante), o monumento 2 da Serra da Muna (Viseu) (CRUZ et al. 1998), o conjunto de tumuli da Sr. ${ }^{a}$ da Ouvida (Castro Daire) (CRUZ \& VILAÇA 1999 a), ou de modo mais expressivo a necrópole do Paranho (Tondela) (COElHO 1925, CRUZ 1997).

As práticas e crenças associadas à morte em finais da Idade do Bronze no Centro de Portugal foram recentemente alvo de sistematização e discussão, pelo que não se justifica retomar aqui o assunto de forma muito desenvolvida (VILAÇA 2014, 2017).

Encarava-se então a morte de forma não hegemónica, estando registadas soluções várias a diversos níveis (VILAÇA \& CRUZ 1999b, VILAÇA 2014, 2017). Não obstante as particularidades de cada caso, é possível identificar um conjunto de soluções que sistematizamos da seguinte forma: primeiro, a adoção explícita de um novo ritual funerário, a incineração; segundo, a continuidade de outros rituais, como a inumação, excecionalmente bem preservada no enterramento duplo da Roça do Casal do Meio (Sesimbra) (SPINDLER et al. 1973-74); por fim, e ainda que não demonstrável de forma consistente em termos empíricos, a possível deposição de corpos na água, ou a sua exposição ao ar livre, soluções que poderiam ter sido igualmente praticadas, conforme foi já sustentado (VILAÇA \& CRUZ 1999: 76, VILAÇA 2017: 116-117).

Em relação à incineração, assume particular relevância a prática específica da deposição dos restos humanos cremados, com recolha total ou parcial, em recipiente cerâmico e, por vezes, incorporando também o designado "espólio funerário", como sucedeu em Souto 1.

Tal como os dados da escavação indicam, a cremação do corpo foi feita conjuntamente com adereços em bronze, decerto e pelo menos braceletes, por isso estão deformados e fragmentados, que poderiam associar-se diretamente ao defunto. Esse interessante ritual repercute-se nas dificuldades que coloca a nível identificativo, na medida em que se colocam outras hipóteses, como se referiu.

Por outro lado, é manifesto que o ritual de cremação com deposição em urna neste período tem, no extremo ocidental da Península Ibérica, uma geografia muito peculiar, ainda que diversa (veja-se o caso da necrópole do Paranho, antes referida), que the confere alguma expressividade. Trata-se do que se designou como "Linha do Tejo", uma vez que em ambas as suas margens são conhecidos diversos testemunhos com incinerações em recipiente cerâmico (VILAÇA 2014, 2017). O monumento de Souto 1, que dista apenas cerca de $15 \mathrm{Km}$ do grande rio peninsular, inscreve-se nesse 
conjunto de situações de que também fazem parte, além de outros pior conhecidos, como a Quinta da Alorna (Almeirim), Salvaterra de Magos, Almoster, talvez ainda Santarém (VILAÇA 2014), as duas estruturas do Monte de São Domingos (Castelo Branco) (CARDOSO et al. 1998) e os cemitérios polinucleados de Alpiarça, com o Cabeço da Bruxa, Tanchoal e Meijão (VILAÇA et al. 1999, com demais bibliografia) (Fig. 11).

Por último, verifica-se uma notável sintonia, mesmo genérica, ao longo do Tejo, a nível da cronologia dos contextos com incinerações em urna, justamente na viragem do milénio — séc. XI-X/IX
a.C. - , conforme indicam as datas de 14Carbono existentes (VILAÇA 2017), a que se deve juntar a data do Monte de São Domingos, entretanto divulgada (BRANDHERM et al. 2017) e a que acresce a nova data aqui publicada. Tal sintonia permite pensar ainda numa rápida adoção deste ritual, que, aparentemente, tem também sucesso durante um período de tempo não muito largo.

A realidade aqui apresentada sumariamente revela, no conjunto, o inequívoco papel do Tejo enquanto eixo estruturante de conexões, da mobilidade de pessoas e circulação de ideias, neste caso da transmissão de um novo ritual e ideologia.

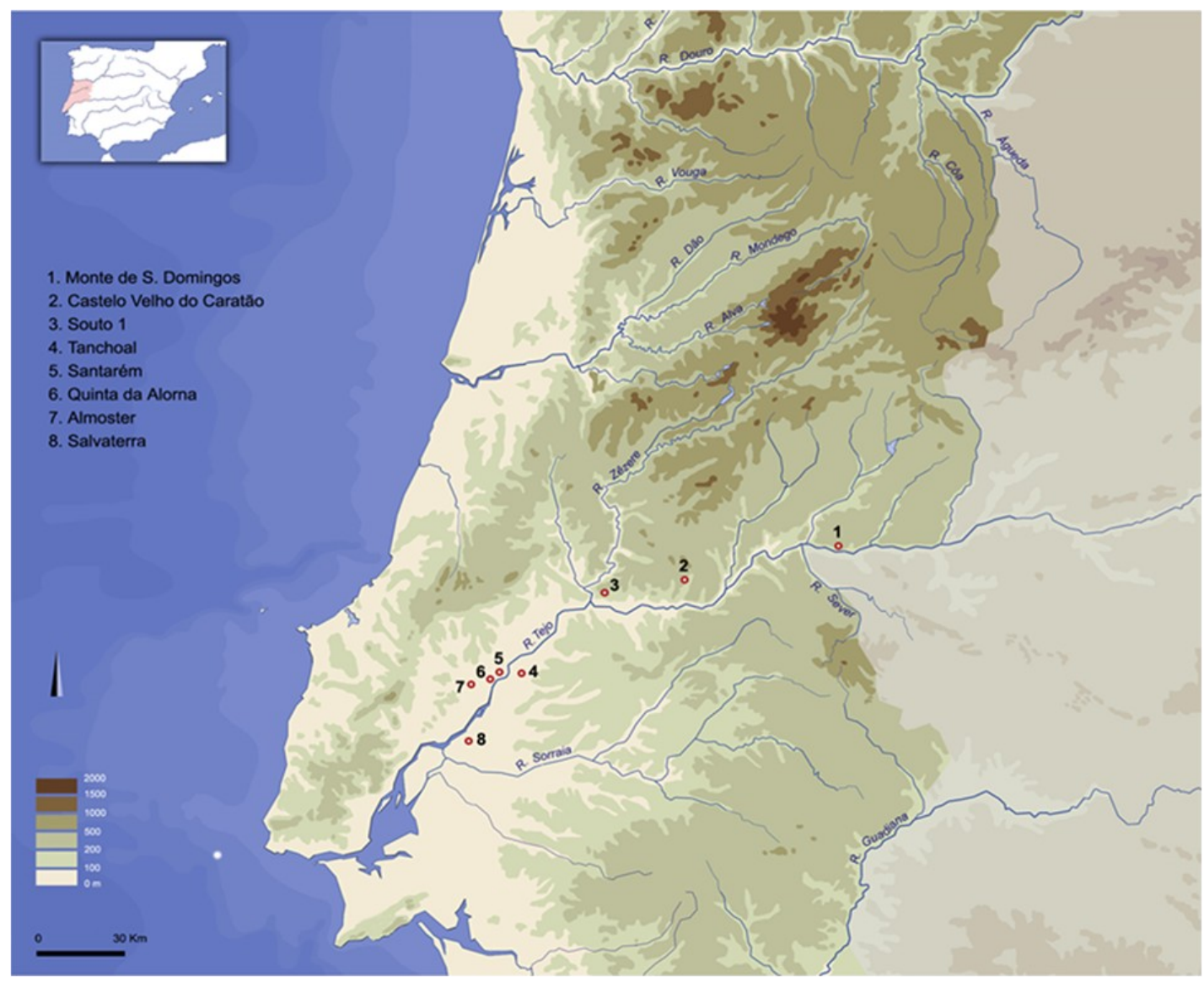

Fig. 11. Contextos funerários com incinerações na "Linha do Tejo" (in Vilaca 2014, Fig. 11-6, adaptada).

Fig. 11. Funerary context whit incinerations on the "Tejo line" (in VilACA 2014, Fig. 11-6, adapted).

\section{NOTA FINAL}

O estudo arqueométrico dos materiais metálicos e cerâmicos do Tumulus 1 de Souto, objetivo principal do presente texto, permitiu a caraterização de um contexto funerário de cremação com deposição em urna que no extremo ocidental da Península Ibérica tem um âmbito geográfico localizado, a que se chamou "Linha do Tejo", enquadrado entre os séculos XII-X A.C. Do ponto de vista tecnológico, os fragmentos de metal analisados enquadram-se na tradição metalúrgica do Bronze
Final da região, como confirmado também através do estudo do fragmento de cerâmica da grande urna.

Não obstante, nem tudo ficou perfeitamente esclarecido, em concreto as causas diretas responsáveis pelas marcas/incrustações encontradas na superfície do pequeno púcaro, as quais, todavia, pela regularidade que exibem, comprovam a manipulação intencional do bronze colocado em contacto com aquela. A observação dessa realidade e os resultados do estudo aqui disponibilizados, que importa aprofundar, demonstram como a sofistica- 
ção tecnológica das comunidades de há 3000 anos e suas práticas rituais continuam a traduzir-se num processo de aprendizagem.

\section{BIBLIOGRAFIA}

Bottaini, C. 2012. Depósitos metálicos no Bronze Final (sécs. XIII-VII a.C.) do Centro e Norte de Portugal. Aspectos Sociais e Arqueometalúrgicos. Tese de doutoramento, Universidade de Coimbra.

Bottaini, C.; Vilaça, R., Schiavon, N., Mirão, J., CanDEIAS, A., Bordalo, R., PATERnOSTER, G. \& Montero-Ruiz, I. 2016. New insights on Late Bronze Age Cu-metallurgy from Coles de Samuel hoard (Central Portugal): A combined multianalytical approach. Journal of Archaeological Science: Reports, 7: 344-357.

Brandherm, D.; Krueger, M. \& CARdoso, J. L. 2017. Um novo método para a datação absoluta de ossos humanos cremados: a cabana 2 do Monte de São Domingos (Malpica do Tejo, Portugal). Estudos Arqueológicos de Oeiras, 23, 2016-2017: 519-530.

CANHA A.; VAlÉrio P. \& ARAúJo M.F. 2007. Testemunhos de metalurgia no povoado de Canedotes (Bronze Final). Revista Portuguesa de Arqueologia, 10 (1): 159-178.

Cardoso, J.L.; Caninas, J.C. \& Henriques, F. 1998. Duas cabanas circulares da Idade do Bronze Final do Monte de São Domingos (Castelo Branco). Estudos Pré-históricos, VI: 325-345.

Coelho, J. 1925. A Necrópole do Paranho, Viseu, Tipografia popular /ed. do autor.

Cordier, G. 1975. Les Tumulus hallstattiens de Sublaines (Indre-et-Loire). I Étude archéologique, L'Anthropologie, 79 (3): 451-482.

Costantinides I.; Adrianes A. \& Adams. F. 2002. Surface characterization of artificial corrosion layers on copper alloy reference materials. Applied Surface Sciences 189: 90-101.

Cruz, D.J. 1997. A necrópole do Bronze Final do "Paranho" (Molelos, Tondela, Viseu). Estudos Préhistóricos, V: 85-109.

Cruz, D.J.; Gomes, L.F. \& Carvalho, P.S. 1998. Monumento 2 da Serra da Muna (Campo, Viseu). Resultados preliminares dos trabalhos de escavação. Estudos Pré-históricos, VI: 375-395.

CruZ, D.J. \& VilaÇA, R. 1999. O grupo de tumuli da Senhora da Ouvida (Monteiras/Moura Morta, Castro Daire, Viseu). Resultados dos trabalhos arqueológicos. Estudos Pré-históricos, VII: 129-161.

CRUZ, A.R. 2011. A Pré-História Recente do vale do baixo Zêzere. Arkeos - Perspectivas em Diálogo. Tomar: Centro Europeu de Investigação da Pré-História do Alto Ribatejo. Vol. 30.

Cruz, A. \& GraçA, A. 2013. A Vida e a Morte na PréHistória Recente do Concelho de Abrantes. In I. Jana, G. Pocaterro \& D. Delfino (coord), Actas II e III Jornadas Internacionais do MIAA, Abrantes, Câmara Municipal de Abrantes, $1^{\mathrm{a}}$ ed.: 137-145.

Cruz, A.; Delfino, D. \& GraçA, A. 2013. Pensar a Morte no Alto Ribatejo: Tumulus 1 do Souto (Abrantes, Portugal). In M. Albuquerque, S. Borges \& L. Oosterbeek (Coord.), Identidades e Diversidade Cultu- ral - Patrimônio arqueológico e antropológico do Piaui-brasil e do Alto Ribatejo-Portugal, TeresinaTomar: FUNDAC - CEIPHAR/ ITM: 49-65.

Cruz, A.; GraçA, A., Delfino D. \& OosterbeeK, L. 2014a. A Integridade da Paisagem Antropizada do Alto Ribatejo. In J. Campos, J. Zocche, J. Cerezer \& L. Oosterbeek (Coord), Arqueologia IberoAmericana e Transatlântica. Arqueologia, Sociedade e Território, Criciúma: UNESC- ITM: 17-39.

Cruz, A.; GraçA, A. \& Oosterbeek, L. 2014b. Caves, Megalithism and Tumuli - Three diachronic realities in funerary archaeology from Alto Ribatejo. In A. Cruz, E. Cerrillo-Cuenca, P. Bueno Ramirez, J. Caninas \& C. Batata (coord), Rendering Death: Ideological and Archaeological Narratives from Recent Prehistory (Iberia), Proceedings of the Conference held in Abrantes, Portugal, 11 May 2013 Archaeopress. BAR International Series 2648, Oxford, Hadrian Books, Ltd: 61-75.

Cruz, A.; Delfino, D., Gaspar, F., Batista, A. 2015. Circulação de artefactos, ideias e matérias-primas no Médio Tejo entre o Neolítico Antigo e a Idade do Bronze Final. In A. Cruz, E. Cerrillo Cuenca, E. \& L. Dias (coord), Actas da $2^{a}$ Mesa-redonda Peninsular, Tomar, Centro de Pré-História do Instituto Politécnico de Tomar: 13-26.

CruZ, A. 2016a. Middle Tagus Region and the autochthonous evidences in Late Bronze Age I (Central Portugal). In Sîrbu, V. \& Schuster, C. (coord), Aegean - Mediterranean imports and influences in the graves from the Continental Europe - Bronze and iron Ages, Proceedings of the XVII UISPP World Congress (1-7 September 2014, Burgos, Spain), Oxford, Archaeopress Publishing Ltd. vol. 9: 171186.

CRUZ, A. 2016b. Reciprocity $\leftrightarrow$ Mutuality: Funerary Behaviour in Middle Tagus Region (Central Portugal). In P. Bueno Ramirez (coord), Arqueología y Prehistoria del Interior peninsular, 04 Extra. Homenaje a Rodrigo Balbín Behrmann, Madrid, Area de Prehistoria, Universidad de Alcalá de Henares. p. 191204. Cruz, D.J. 1997. A necrópole do Bronze Fina do "Paranho" (Molelos, Tondela, Viseu). Estudos Pré-históricos, V: 85-109.

Delfino, D.; CruZ, A., GraÇA, A., Gaspar, F. \& Batista, A. 2014. A Problemática das Continuidades e Descontinuidades na Idade do Bronze no Médio Tejo Português. In A. Cruz. (coord) Actas da MesaRedonda "A Idade do Bronze em Portugal: os dados e os problemas." (28 e 29 de Abril de 2014), Antrope Monográfica, Tomar: Centro de PréHistória do Instituto Politécnico de Tomar. $\mathrm{n}^{\mathrm{o}} 1$ (Julho): 14-201.

Gutiérrez Neira, P.C.; Zucchiatti, A., Montero-Ruiz, I., Vilaça, R., Bottaini, C., Gener, M. \& Climent- Font, A. 2011. Late Bronze Age hoard studied by PIXE". Nuclear Instruments and Methods in Physics Research B, 269: 3082-3086.

HARDING, A.F. 2003. Sociedades europeas en la Edad del Bronce, Barcelona, Ariel Prehistoria.

Henriques, S.B.A.; NeIVA, A.M.R., Ribeiro, M.L., DuNNING, G.R. \& TAJČMANOVÁ, L. 2015. Evolution of a Neoproterozoic suture in the Iberian Massif, Central Portugal: New U-Pb ages of igneous and metamorphic events at the contact between the Ossa Morena Zone and Central Iberian Zone. Lithos 220 223 (2015): 43-59. 
Ingelbrecht, C.; Adriaens, A. \& MAIER, E. 2001. Certification of arsenic, lead, zinc and tin (mass fractions) in five copper alloys, BCR 691 Report EUR 19778/1. Directorate General for Research, Brussels.

Ingo G.M.; Angelini E., De Caro T., Bultrini G., CALLIARI I. 2004, Combined use of GDOES, SEM+EDS, XRD, and OM for the microchemical study of the corrosion products on archaeological bronzes, Applied Physics A. 79: 199-203

Ingo G.M.; De Caro T., Riccucci C. \& Khosroff S. 2006. Uncommon corrosion phenomena of archaeological bronzes alloys. Applied Physics A, 83: 581588.

Jiménez Ávila, J. \& GARcía CABEZAS, M. 2014. Colonial Process in Southwestern Iberian Early Iron Age: new burial evidence from "El Molino de Abajo" (Villafranca de los Barros - Extremadura Spain). In J.M. Álvarez, T. Nogales, T. \& I. Rodà (coord.) Actas XVIII CIAC - Congreso Internacional Arqueología Clásica, Mérida: 459-462.

Kalb P. \& Hock M. 1981. Cabeço da Bruxa, Alpiarça (distrito de Santarém). Relatório preliminar da escavação de Janeiro e Fevereiro de 1979. Portugalia, nova série, 2-3: 61-73.

Maggetti, M.; Neururer, CH. \& Ramseyer, D. 2011. Temperature evolution inside a pot during experimental surface (bonfire) firing. Applied Clay Science, vol. 53, Issue 3: 500-508.

Maity, C.; Rousseau, J. \& Le Carlier de Veslud, C. 2013. Le vase à décor de lameles d'étain de $\mathrm{La}$ Jardelle à Dissay, Vienne. Étude préliminaire. Bulletin APRAB, 11: 103-107.

Maritan L.; Nodari, L., Mazzoli, C., Milano, A. \& RusSO, U. 2006. Influence of firing condition on ceramic products: Experimental study on clay rich in organic matter. Applied Clay Science 31: 1-15.

Orton, C. \& Hughes, M. 2013. Pottery in Archaeology. Cambridge University Press.

Reimer, P.J.; BAIllie, M.G.L., BARD, E., BAYliss, A., BECK, J. W., Bertrand, C.J.H., BlACKWELl, P.G., Buck, C.E., Burr, G.S., Cutler, K.B., DAmON, P.E., EdWARDS, R.L., FAIRBANKS, R.G., FrIEDrich, M., GuILderson, T.P., HogG, A.G., Hughen, K.A., Kromer, B., McCromac, G., Manning, S., Bronk Ramsey, C., ReIMER, R.W., Remmele, S., Southon, J.R., Stuiver, M., TAyLOR, F.W., VAN DER PLICHT, J., WEYHENMEYER, C.E. 2004. IntCal04 Terrestrial radiocarbon age calibration, 0-26 cal KYR BP. Radiocarbon, Vol. 46, 3: 1029-1058.

SILVA, A.F. 2016. Enquadramento Geotectónico e a Relação Entre a Tectónica e os Traçados Fluviais da Região Centro-Nordeste de Portugal. Boletim de Minas. Lisboa: Direção Geral de Energia e Geologia, vol. 51, 2: 48. ISSN: 00008-5935.

QueIroz, P. \& CRuZ, A. 2018. Frutos de roseira na urna funerário do Tumulus 1 do Souto (Abrantes, Portugal). Al-madan online In Raposo, J. (dir.) Al-madan online. Almada: Centro de Arqueologia de Almada. II Série, nº 22. Tomo 1I. Julho: 138-140.
RobBiola L.; Blengino J.M. \& Fiaud C. 1998. Morphology and mechanisms of formation of natural patinas on archaeological Cu-Sn alloys. Corrosion Science, 40 (12): 2083-2111.

ScotT, D.A. 1985. Periodic Corrosion Phenomena in Bronze Antiquities. Studies in Conservation, Vol. 30, 2: 4957.

ScotT, D.A. 1991. Metallography and Microstructure in Ancient and Historic Metals, The J. Paul Getty Trust.

SPINDLER, A.; BRANCO, A.C.; ZBYSZEWSKy, G. \& FERREIRA, O.V. 1973-74. Le monument à coupole de l'âge du Bronze final de la Roça do Casal do Meio (Calhariz). Comunicações dos Serviços Geológicos de Portugal, LVII: pp. 91-154.

TOMÉ, T. 2008. Tumulus 1 do Souto (Abrantes). Analisé preliminar dos restos humanos de um depósito de cremação em urna da idade do Bronze, Relatório de estudo preliminar, IPT-Tomar, policopiado.

VILAÇA, R. 1997. Metalurgia do Bronze final da Beira Interior. Revisão dos dados à luz de novos resultados. Estudos Pré- históricos, 5: 123-154.

VILAÇA, R. \& CRUZ, D.J. 1999. Práticas funerárias e cultuais dos finais da Idade do Bronze na Beira Alta. Arqueologia, 24, Porto: 73-99.

VilaçA, R.; Cruz, D.J. \& Gonçalves, A.H.B. 1999. A necrópole de Tanchoal dos Patudos (Alpiarça, Santarém). Conimbriga, XXXVIII: 5-29.

Vilaç, R.; Almeida, S., Bottaini, C., Marques, J.N. \& MonTERO- Ruiz, I. 2012. Metalurgia do castro do Cabeço da Argemela (Fundão): formas, conteúdos produções e contextos. In Martins, C.M.B., Bettencourt, A.M., Martins, J.I. \& Carvalho, J. (Coord), Povoamento e Exploração de Recursos Mineiros na Europa Atlântica Ocidental, Actas do $1^{\circ}$ Congresso Internacional, Braga, CITCEM: 427-452.

VILAÇA, R. 2014. The Faces of Death: from the Bronze to the Iron Age, between the North and the South of the Portuguese territory. In Cruz, A., CerrilloCuenca, E., Bueno Ramírez, P., Caninas, J.C. \& Batata, C. (Coord.), Rendering Death: Ideological and Archaeological Narratives From Recent Prehistory (Iberia). BAR International Series 2648: 125-138.

VILAÇA, R. 2017. Da morte e seus rituais em finais da Idade do Bronze no Centro de Portugal: 20 anos de investigação. Estudos Pré-históricos, 17, 2012 (Actas da Mesa-Redonda "A Pré-história e a Proto-história no Centro de Portugal: avaliação e perspectivas de futuro"): 101-133.

WAdsaK, M.; Constantinides, I., VitTiglio, G., Adriaens, A., Janssens, K., Schreiner, M., Adams, F. C., Brunella, P. \& Wuttmann, M. 2000 Multianalytical Study of Patina Formed on Archaeological Metal Objects from BliesbruckReinheim. Mikrochim. Acta 133: 159-164. 